made by the Journal over the past years. The excellent standard of the contents and its educative value are widely acknowledged, and it has truly become an international publication. Its free online access is widely utilized and has been very beneficial to readers from countries with limited resources. The indexing and impact factor have increased. The physical qualities of the publication (quality of paper, reproduction of figures, overall attractiveness) are much better.

I wish Indian Pediatrics continued growth and all round excellence.

\section{REFERENCES}

1. Srivastava RN. Literature pollution. Indian Pediatr. 1985; 22: 331-332

2. Srivastava RN, Manmohan, Sachdev HPS, Puri RK. Emergencies in Pediatrics. Indian Pediatr. 1986; S;23.

3. Srivastava RN, Manmohan, Sachdev HPS, Puri RK. Pediatric and Neonatal Emergencies. New Delhi: Cambridge Press; 1991.

4. Srivastava RN. $25^{\text {th }}$ year of Indian Pediatr. Indian Pediatr. $1988 ; 25: 3-4$.

\title{
Contributing to Growth of Indian Pediatrics
}

\section{H P S SACHDEV}

Editor, Indian Pediatrics (December 1994-2001)

Correspondence to: HPS Sachdev, Senior Consultant Pediatrics and Clinical Epidemiology,

B-16Qutab Institutional Area, New Delhi 110016, India.hpssachdev@gmail.com

Between 1985 and 1994, I became familiar with the editorial processes of Indian Pediatrics in various capacities as a Member, Assistant Editor and Publication Secretary of the Journal Committee. Then in late 1994, an unexpected telephonic call informed me of the Executive Committee's decision to immediately elevate me to the helm of affairs. I assumed charge of the editorial process with mixed feelings of disbelief, deep gratitude and anxiety at the onerous responsibility entrusted upon me at a relatively young age. The challenge for me was to not only continue the journal's rapid growth trajectory with the available meager resources but also to make it more influential for clinical practice and public health policy.

The newly constituted think-tank was in substantial agreement with the following envisaged role of journals and editors, particularly in our setting: "the prime task of an editor is to produce a journal that people will want to read. If the end product is mere units of research, these could just as well be placed directly into databases. Journals must explain, stimulate, provide a forum for discussion, and at times, make readers angry!" [1]. Being a researcher at the core, I instinctively sought robust evidence to guide our future efforts. After substantial introspection, discussion with close friends and some literature search, we concluded that our art of editing has had minimal, if any, formal research input, particularly from the target audience. It therefore seemed logical to continue editing with skills imbibed as an "apprentice" while accumulating evidence on a priority basis to guide further action.

\section{Translating Evidence into ACtion}

The National Conference of Indian Academy of Pediatrics provided a golden opportunity for conducting qualitative research through in-depth interviews and focused group discussions. This was supplemented with a quantitative "Opinion poll for the desirable content of Indian Pediatrics" in the January 1995 issue [2].

A particularly disconcerting observation was the candid admission by some practitioners that they did not even open the issue because the "contents were not useful, attractive, interesting, stimulating or understandable". We then realized that a delicate balance will have to be struck between the aspirations of academicians and active researchers on one hand and the practitioners, particularly in remote areas, on the other hand. The following specific suggestions helped us to fine tune the internal processes and shape the future content of Indian Pediatrics: (i) The journal should have "something of interest for everybody in the target audience"; (ii) "Original Articles" should be subjected to more rigorous epidemiological cum statistical review and their Abstracts should be presented in a structured format; (iii) Content of interest to practitioners must be increased 
by including features relevant to everyday practice, selected summaries of latest relevant research conducted abroad, and dialogues with authorities on important topics; and (iv) Publication of rare well defined syndromes must be drastically reduced or stopped [2].

The journal committee endorsed the decision to immediately act according to the gathered evidence. Some of the proposed modifications were rapidly acted upon while others had a relatively long gestation period as the contents till August 1995 had already been finalized.

Our actions were in consonance with the prevalent global trend of evidence based editing. Medical journals were increasingly being transformed on the basis of collected scientific information on various aspects of the editorial process including content design, style and format, authorship, peer review, publication ethics, editing, and relationship with the industry. Realizing the importance of this issue, the World Association of Medical Editors was launched in Bellagio, Italy on 6 March, 1995 to foster international cooperation among editors of peer-reviewed medical journals. We kept ourselves abreast of these international developments and repeatedly accumulated relevant evidence applicable to our scenario to continually shape the journal. The latter was achieved through perpetual interaction with readers by the members of the journal committee and the national advisory board.

Medical journals at that time were differentiated into two main categories, namely, "recorder journals" and "newspaper journals" [3,4]. Recorder journals came close to the desired function of a journal from the point of view of the author; they were not really meant to be read, but only to deposit science for future reference which is undoubtedly important since science does not exist until published [4]. General journals -newspaper journals - by contrast, had other aims: they were active shapers of knowledge and of opinions [4]. They were expected to "inform, interpret, criticize, and stimulate" [3] and also retain some recorder function, at least for important facts [4].

On the basis of collected evidence and global trends, Indian Pediatrics gradually shifted its focus from a predominantly recorder journal towards a newspaper journal [5]. To make the journal more educative, interactive, entertaining, and "reader friendly", a variety of sections were introduced including Immunization Dialogue, Readers' Forum, Viewpoint, News in Brief, Clippings, Selected Summaries, Personal Practice, Recommendations, Reports, Clinicopathological Conferences and Images in Clinical Practice. The reporting format was also molded according to the prevalent international recommendations including recording of key messages for rapid browsing, specific contribution by individual authors like film credits, competing interests, and sources of funding.

We also yielded to the consumer demand of enhancing production quality within our available resources; the journal cover was changed to laminated art card instead of art paper and better quality print paper was utilized inside.

All these modifications proved vital for making Indian Pediatrics more vibrant and improving it's "readability and utility index".

\section{Supporting Editorial Processes}

Simultaneous vigilance over crucial editorial components made editing more efficient and transparent. This was achieved through regular input from journal committee meetings. Important aspects included anonymous reviews, transparency in decision making irrespective of the reputation or clout of the authors, communicating the reasons for rejection to authors, taking decisions in a strict time bound manner with constant monitoring of pending manuscripts, and hunting for new reviewers who were willing to provide requisite quality input within the stipulated time limit. The quality bar for acceptance of manuscripts was raised. I had no hesitation in rejecting a research manuscript co-authored by me on the basis of peer review. The acceptance rate of the manuscripts gradually reduced from around $55-60 \%$ to $16-20 \%$. This undoubtedly ruffled several feathers but ultimately enhanced the quality of publications substantially, which was appreciated by the mainstream audience. These changes also motivated some reputed Indian researchers to submit their work to Indian Pediatrics in preference to international journals.

We proactively solicited editorial and research contributions on topical issues and peer review from international authorities, particularly non resident Indians; sometimes personal contacts proved very useful for this purpose. This provided some international lustre to the journal.

Publication ethics were monitored more stringently. This was necessitated by instances of duplicate publication, gift authorship and questionable data integrity that were brought to our notice by vigilant readers and referees [6]. The Journal Committee did not push these issues under the carpet but took appropriate action on the basis of the International Committee on Publication Ethics guidelines. 
A close liaison was maintained with the Cambridge press and the postal authorities to ensure strict timeliness of posting. The contents were kept finalized for the next three months to preempt any unforeseen circumstances. With these measures, all the 85 issues during my tenure were ready and posted on time.

\section{LAUnChing The Electronic Version}

Traditional paper periodicals were facing annihilation or being relegated to a poor second place. Moving with the times, we also introduced a modest "electronic version" of Indian Pediatrics with an envisaged complementary role, in April 1998. Subsequently, in late 1999, Indian Pediatrics too launched the full text dynamic web site. This development represented a pioneering effort amongst Asian medical journals. Despite potential loss of international subscription revenue, we deliberately kept the access to our electronic version free of cost. These measures enhanced the global visibility, stature and scientific quality of Indian Pediatrics. The average access rate of 4500 per week in December 1999 bears ample testimony to the overwhelming importance of the launched "electronic version". Further, with this development, international indexing of published articles was achieved within one week.

\section{Fiscal Health}

There was an urgent need to transform the fiscal balance from negative to positive to ensure effective operationalization of the envisaged modifications. The IAP constitutional mandate of sending the monthly issue to all members free of charge was a steadily growing drain on the journal's fiscal health because the central contribution was barely sufficient to meet one-third of the production costs. We adopted a dual strategy to improve fiscal health. Expenses were curtailed by resorting to hard negotiations with the publication house, saving on editing and proof reading expenses by in-house efforts, procuring paper directly from the market, multi-tasking by the skeletal staff and so forth. Finances were also raised by tapping all possible "ethical" resources including proactive colored advertisement support from industry other than Infant Milk Substitute Manufacturers, royalty from Indian Pediatrics produced books, tapping international agencies, charging for excessive reprints or pages, and putting unused money in short term fixed deposits. These measures proved successful in substantially improving the fiscal health so that we could initiate the desired changes.

\section{BOOSTING THE INFRASTRUCTURE}

Indian Pediatrics was operating from a small (100 square feet) rented room with a skeleton staff of two secretaries and two class IV workers. Contrast this with the Lancet Editor's statement at that time that "he finds 12 full-time editors and a total staff of 50 inadequate" [1]. The augmented financial resources helped us to boost the infrastructure and staff support. Notable milestones included augmentation of secretarial assistance, procurement of a small office space in a commercial complex along with rented space, shifting from typewriters to computers, buying printers and photocopier, and getting internet access. The staff gladly provided dedicated input as they received salary commensurate with the corresponding government scales and promotion. All these factors contributed in substantial measure to the journal production and its quality.

\section{Concluding Comments}

I consider myself to be blessed at being provided this opportunity of contributing to the growth of Indian Pediatrics. It was possible to achieve something only because of God's grace, the strong foundation laid by my predecessors, the endorsement of the target audience, the contributors' input, continued selfless devotion of the Journal Committee members, National Advisory Board and peer reviewers, support of IAP Executive Board and Office Bearers, Cambridge Press and last but not the least, the dedicated journal staff.

\section{REFERENCES}

1. Pandya SK. Indian Medical Journals and Medicine and the Indian Media, All India Institute of Medical Sciences, New Delhi, 5 September, 1994. Natl Med J India. 1994;7:295-7.

2. Sachdev HPS. From the editor's pen. Indian Pediatr. 1995;32:4-5.

3. Fox T. Crisis in Communication: The Functions and Future of Medical Journals. London: Athlone Press; 1965.

4. Vandenbroucke JP. Medical journals and the shaping of medical knowledge. Lancet. 1998;352:2001-6.

5. Sachdev HPS. From the editor's pen. Indian Pediatr. 1999;36:9-10.

6. Sachdev HPS. Stepping into Y2K. Indian Pediatr. 2000;37:7. 